\title{
Microbiological aspects of ozone: bactericidal activity and antibiotic/antimicrobial resistance in bacterial strains treated with ozone
}

\author{
Giuseppe Giuliani, ${ }^{1,2}$ Giovanni Ricevuti, ${ }^{2,3}$ Antonio Galoforo, ${ }^{2,4}$ Marianno Franzini2,5 \\ ${ }^{1}$ Servizio di Medicina di Laboratorio ASST-Rhodense, Rho (MI); ${ }^{2}$ Italian Society for Oxygen-Ozone Therapy (SIOOT), \\ Gorle (BG); ${ }^{3}$ Department of Internal Medicine, University of Pavia; ${ }^{4}$ Pio Albergo Trivulzio, Milan; ${ }^{5}$ SIOOT International \\ President, Italy
}

\begin{abstract}
Antimicrobial resistance is one of the most complex global health challenges today. The world has long ignored warnings that antibiotics and other medicines are losing their effectiveness after decades of overuse and misuse in human medicine, animal health and agriculture. Common illnesses like pneumonia, postoperative infections, diarrhoeal and sexually transmitted diseases, as well as the world's largest infectious disease killers - tuberculosis (TB), HIV and malaria - are increasingly becoming untreatable because of the emergence and spread of drug resistance. Worsening antimicrobial resistance could have serious public health, economic and social implications. The threat of antimicrobial resistance is also becoming a key consideration for programmes addressing maternal and child health, sexual and reproductive health, foodborne diseases, water and sanitation, and infection prevention and control. Although the 21 st century is being shaped by technology and innovation, humans could soon find themselves in an era where simple infections once again kill millions every year. The past three years have seen unprecedented global political momentum to address antimicrobial resistance: in 2015, governments adopted a global action plan at the World Health Assembly and in 2016 passed a political declaration at the United Nations General Assembly. Antimicrobial resistance has made it onto the agendas of the G7 and G20 groups and is a core component of the Global Health Security
\end{abstract}

Correspondence: Giuseppe Giuliani, Italian Society for OxygenOzone Therapy (SIOOT), Via Don Luigi Sturzo 2, 24020 Gorle (BG), Italy.

E-mail: info@ossigenoozono.it

Key words: Ozone; Antimicrobial resistance; Microbiology.

See online appendix for Supplementary Tables.

Received for publication: 3 December 2018.

Accepted for publication: 5 December 2018.

CCopyright G. Giuliani et al., 2018

Licensee PAGEPress, Italy

Ozone Therapy 2018; 3:7971

doi:10.4081/ozone.2018.7971

This article is distributed under the terms of the Creative Commons Attribution Noncommercial License (by-nc 4.0) which permits any noncommercial use, distribution, and reproduction in any medium, provided the original author(s) and source are credited.
Agenda. WHO is working closely with the Food and Agriculture Organization of the United Nations and the World Organization for Animal Health in leading global efforts against antimicrobial resistance and ensuring that the necessary momentum is consolidated and sustained. These efforts are guided by an ad-hoc interagency coordination group established in 2017. A global development and stewardship framework to combat antimicrobial resistance is being drafted to support the development of new antimicrobial medicines, diagnostics, vaccines and other tools. One of the gravest global concerns about antimicrobial resistance currently is that antibiotic resistance has emerged in so many pathogens, including TB. In 2016, at the high-level meeting of the UN General Assembly on antimicrobial resistance, Heads of State directed an unprecedented level of attention to curbing the spread of infections that are resistant to antimicrobial medicines. They reaffirmed their commitment to stopping the misuse of antimicrobial medicines in human health, animal health and agriculture, and recognized the need for stronger systems to monitor drug-resistant infections and the amounts of antimicrobials used in humans and animals. In the wake of the increasing global awareness of the need for new antibiotics, Member States highlighted market failures, and called for new incentives for investment in research and development of new, effective and affordable medicines, rapid diagnostic tests, and other important therapies to replace those that are losing their effectiveness. In response to this and in line with the Global Action Plan on Antimicrobial Resistance to support the identification of pathogens of greatest concern, WHO developed a priority list of antibiotic resistant bacteria to underpin renewed efforts for the research and development of new antibiotics. The only possible defence against the threat of antimicrobial resistance and the (very real) possibility of a post-antibiotic era is a global and coordinated effort by all stakeholders to support other important therapies such as the Oxygen-Ozone $\left(\mathrm{O}_{2} \mathrm{O}_{3}\right)$ therapy. As a result, the scope and focus of the work underlying this dissertation was to study the application of $\mathrm{O}_{2} \mathrm{O}_{3}$ therapy towards several resistant bacteria. Moreover, we evaluated three different framework for gut bacteria, skin and soft tissue infections and mucosal infections.

\section{Introduction}

Christian Friedrich Schonbein (1799-1868) discovered ozone in 1840, when, working with a voltaic pile in the presence of oxygen, noticed the emergence of a gas with an electric and pungent smell that could be a sort of super-active oxygen. $\mathrm{O}_{3}$ results from the rearrangement of atoms when oxygen molecules are subjected to high-voltage electric discharge. 
Although Schonbein had probably guessed that ozone could be used as disinfectant, his intuition did not save him when he contracted a Bacillus anthracis infection while exploring a chemical method for preserving meat. The concept that ozone derives from oxygen when an electric discharge was generated by a voltaic arc was practically applied by the chemist Werner von Siemens, who invented the so-called super-induction tube (Siemens's tube), consisting of two interposed electrode plates set at a high voltage which, in the presence of oxygen, could generate some ozone. It became possible to produce ozone at will and clarify that ozone is indeed a very reactive, unstable and unstorable gas that had to be produced ex tempore from oxygen and used at once. Industrial ozone generators could then be used for industrial application and disinfection of water, after it was shown the potent and broad bactericidal activity of ozone. Today nobody doubts about its strong disinfectant properties and there are more than 3,000 municipal treatment facilities in the world. As the need of water increases daily and it is indispensable to prevent the spread of infectious diseases, the importance of ozone for practical applications becomes immense. The first medical application seems to have been the use of ozone for treating gaseous, post-traumatic gangrene in German soldiers during the First World War. However a big step forward was the invention of a reliable ozoniser for medical use by the physicist Joachim Hansler (1908-1981). The idea to use ozone in medicine developed slowly during the last century and it was stimulated by the lack of antibiotics and the disinfectant properties of ozone. Not surprisingly a Swiss dentist, E.A. Fisch (1899-1966) was the first to use ozone in his practice. By a twist of fate, Dr. E. Payr (1871-1946), a surgeon had to be treated for a gangrenous pulpite and soon realized the efficacy of the ozone treatment in surgery to become so enthusiastic to report his results at the 59th Congress of the German Surgical Society in Berlin (1935) and write: Which other disinfectant would be tolerated better than ozone? The positive results in $75 \%$ of patients, the simplicity, the hygienic conditions and innocuity of the method are some of the many advantages. In 1936, in France, Dr. P. Aubourg proposed to use the insufflation of oxygen-ozone into the rectum to treat chronic colitis and fistulae. Physicochemical properties of ozone are closely related to its efficacy against microorganisms.

\section{Solubility, stability and reactivity of ozone}

The gas does not react with water; therefore it forms a true physical solution. ${ }^{1}$ Dissolution of gasses that are partially soluble in water (for example, ozone) follows Henry's law which states that the amount of gas in solution, at a given temperature, is linearly proportional to the partial pressure of the gas. Solubility ratio for ozone increases as the temperature of water decreases. ${ }^{2}$ These authors showed a negative logarithmic relationship between the solubility ratio and water temperature in the range of $0.5^{\circ} \mathrm{C}$ to $43^{\circ} \mathrm{C}$. Other parameters influence the dissolution of ozone in water. For example, when a solution is prepared by bubbling ozone in water, smaller bubble sizes result in larger surface area of contact which increases the solubility. ${ }^{3}$ These authors demonstrated that an optimum dissolution of ozone in water occurs when bubbles are 1 to $3 \mathrm{~mm}$ in dia. Purity and $\mathrm{pH}$ of water greatly affect the rate of ozone solubilization. $\mathrm{Kim}^{4}$ bubbled gaseous ozone $(1 \mathrm{mM})$ into double distilled, deionized or tap water. Ozone gas dissolved faster in deionized and distilled water than in tap water. The $\mathrm{pH}$ values for deionized, distilled water and tap water (two sources) were 5.6, 5.9 and 8.23/8.39, respectively. These values of $\mathrm{pH}$ indicated that the high $\mathrm{pH}$ of tap water may have interfered with the solubilization of ozone. Moreover, tap water may contain organic matter that consumes ozone and minerals that catalyze ozone decomposition ${ }^{5}$ so that the solubility of ozone increases when puri- ty of water increases. The great solubility of ozone in water allows its immediate reaction with any soluble compounds and biomolecules present in biological fluids.

Ozone is unstable in aqueous solutions. It degrades continuously to oxygen. ${ }^{6}$ The half-life of ozone in distilled water at $20^{\circ} \mathrm{C}$ is generally considered to be 20 to $30 \mathrm{~min}$. However, Wynn et al. ${ }^{7}$ found that ozone has a half-life of $165 \mathrm{~min}$ in distilled water at $20^{\circ} \mathrm{C}$ and Wickramanayake ${ }^{8}$ reported a shorter half-life (2 to 4 min) in aqueous solution at $\mathrm{pH} 7.0$ and $25^{\circ} \mathrm{C}$. The $\mathrm{pH}$ greatly affects the stability of ozone in aqueous solutions. $\mathrm{Kim}^{4}$ demonstrated that the stability of ozone in solution was the greatest when $\mathrm{pH}$ was 5.0. Ozone stability decreased as $\mathrm{pH}$ increased, and no ozone was detected in buffers with $\mathrm{pH}$ 9.0. These data indicate that high $\mathrm{pH}$ and presence of ozone-demand materials enhance decomposition of ozone. Organic and inorganic compounds in aqueous solutions react with ozone in different pathways. ${ }^{9}$ Molecular ozone reactions are selective and limited to unsaturated aromatic and aliphatic compounds. Ozone oxidizes these compounds through cycle-addition to double bonds. ${ }^{2}$ Oxidation of sulfhydryl groups, which are abundant in microbial enzymes, may explain rapid inactivation of microorganisms and bacterial spores by ozone. Ozone reacts with polysaccharides slowly, leading to breakage of glycosidic bonds and formation of aliphatic acids and aldehydes. ${ }^{2}$ Reaction of ozone with primary and secondary aliphatic alcohols may lead to formation of hydroxy-hydroperoxides, precursors to hydroxyl radicals, which in turn react strongly with the hydrocarbons. ${ }^{10}$ Perez et al. ${ }^{11}$ demonstrated that peptidoglycan and in particular N-acetyl glucosamine - a molecule present in the bacterial cell walls of both Gram positive and Gram negative bacteria (mainly in Gram positive bacteria) and in viral capsids - was resistant to the action of ozone in aqueous solution at $\mathrm{pH} 3$ to 7 . This observation may explain, at least in part, the higher resistance of gram-positive bacteria compared to gram negative ones; the former contains greater amounts of peptidoglycan in their cell walls. The action of ozone on amino acids and peptides is significant especially at neutral and basic $\mathrm{pH}$. Ozone attacks the nitrogen atom or the R group or both. Ozone reacts slowly with saturated fatty acids. Unsaturated fatty acids are readily oxidized with ozone and cycle-addition products are formed. Ozone reacts quickly with nucleobases, especially thymine, guanine, and uracil. Reaction of ozone with the nucleotides releases the carbohydrate and phosphate ions. ${ }^{12}$ The rate of destruction of microorganisms by a disinfectant generally increases with increasing temperature. In the case of ozone, however, as temperature increases ozone becomes less soluble and less stable, but the ozone reaction rate with the substrate increases. As the temperature increased from $0^{\circ} \mathrm{C}$ to $30^{\circ} \mathrm{C}$, the rate of inactivating Giardia cysts increased. ${ }^{8}$ However, Kinman ${ }^{13}$ reported that when bacteria were treated with ozone at $0^{\circ} \mathrm{C}$ to $30^{\circ} \mathrm{C}$, treatment temperature had virtually no effect on the disinfection rate. The researcher related this observation to the decrease in solubility and increase in the decomposition and reactivity of ozone as temperature increases. The residual ozone concentration was greatest at the lowest temperature $\left(4^{\circ} \mathrm{C}\right)$ and decreased with increasing temperature. It appears that when treatment temperature increased, the increase in ozone reactivity compensated for the decrease in its stability, and thus no appreciable change in efficacy was observed. Presence of organic substances with high ozone demand may compete with microorganisms for ozone. Viruses and bacteria associated with cells, cell debris, or feces are resistant to ozone, but purified viruses are readily inactivated with the sanitizer. ${ }^{14,15}$ Inactivation of bacteria by ozone is a complex process because ozone attacks numerous cellular constituents such as proteins, unsaturated lipids, respiratory enzymes in cell membranes, peptidoglycan in cell wall, enzymes and nucle- 
ic acids in the cytoplasm, proteins and peptidoglycan in spore coats and viral capsids. As ozone molecules make contact with the cell wall, a reaction called an oxidative burst occurs which literally creates a tiny hole in the cell wall. The bacterium begins to loose its shape while ozone molecules continue creating holes in the cell wall. After thousands of ozone collisions over only a few seconds, the bacterial wall can no longer maintain its shape and the cell dies.

\section{Aims and objectives}

The primary aim of our group of research is to combine the resources in order to address the identification and validation of mechanisms of ozone's bactericidal, virucidal and fungicidal action and treatment.

In this context, we are studying the effects of $\mathrm{O}_{2} \mathrm{O}_{3}$ on the following pathogens:

i) Acinetobacter baumannii; carbapenem-resistant.

ii) Pseudomonas aeruginosa; carbapenem-resistant.

iii) Enterobacteriaceae (Klebsiella pneomoniae, Escherichia coli, Enterobacter spp., Serratia spp., Proteus spp., Providencia spp. and Morganella spp.); carbapenem-resistant, $3^{\text {rd }}$ generation cephalosporin-resistant.

iv) Enterococcus faecium ; vancomycin-resistant.

v) Staphylococcus aureus; methicillin-resistant, vancomycin intermediate and resistant.

The purposes of this study were:

i) to analyze basic bactericidal activity of ozonated suspension of clinical bacterial strains;

ii) to study the fate of antibiotic/antimicrobial resistance in bacterial strains treated with $\mathrm{O}_{2} \mathrm{O}_{3}$.

\section{Materials and Methods}

\section{Microbial strains}

The following 13 clinical bacterial strains of which 6 Gram positive and 7 Gram negative were selected with different susceptibility to antibiotics and chemotherapeutics, mostly, multiresistant, isolated during routine clinical microbiologic investigations from different specimens (samples of urine, sputum, tracheal aspirates, wound swabs) of hospitalized patients (Table 1).

$S$. aureus and $S$. epidermidis isolates were resistant to methicillin, and the enterococcal strains showed resistance to beta-lactams, cephalosporins, imipenem, and trimethoprim/sulfamethoxazole. S. agalactiae isolate was resistant to clindamycin, erythromycin, and tetracycline while C. striatum was resistant to penicillin, ciprofloxacin, gentamicin, tetracycline, and clindamycin. Within the gram-negative rods $E$. coli was resistant to ampicillin, amoxicillin-clavulanate, cefuroxime, and ticarcillin-clavulanate. All three strains of K. pneumonia were carbapenemase producers and the clinical strain isolated from tracheal aspirate was an extensively drug-resistant (XDR) K. pneumonia like A. baumannii. These XDR K. pneumonia/A. baumannii possessed five resistance determinants which contribute to highly resistant to $\beta$-lactam, $\beta$-lactam/inhibitor combinations, aminoglycosides, quinolones, carbapenems, chloroamphenicol and fosfomycin. P. mirabilis isolate was resistant to ampicillin, cefuroxime, ciprofloxacin, colistin, fosfomycin, gentamycin, levofloxacin, norfloxacin, piperacillin, and tobramycin. P. aeruginosa was resistant to levofloxacin, piperacillin, piperacillin-tazobactam, and ticarcillin clavulanate.

All clinical strains were identified by Matrix-assisted laser desorption ionization-time of flight mass spectrometry (BD ${ }^{\mathrm{TM}}$ Bruker MALDI Biotyper ${ }^{\mathrm{TM}}$ System) and the antibiotic/antimicrobial susceptibility testing (AST) by BD Phoenix ${ }^{\mathrm{TM}}$.

\section{Antimicrobial activity determination}

All microbial strains were stored in Microbank vials at $75^{\circ} \mathrm{C}$ until used in the study. Before testing, each bacterial strain was subcultured twice on Tryptone Soya Agar at $37^{\circ} \mathrm{C}$ for 24 hours to ensure viability. Antibacterial activity was evaluated according to EN 1040:2005. One milliliter of standardized bacterial cell suspensions at a density of $1.5 \times 10^{8}$ colony-forming units were ozonated at $40 \mu \mathrm{g} / \mathrm{mL}$ of $\mathrm{O}_{2} \mathrm{O}_{3}$ mixture (produced with the Multiossigen Medical 95 device) at a temperature of $20^{\circ}$ to $22^{\circ} \mathrm{C}$, while the total amount of the $\mathrm{O}_{2} \mathrm{O}_{3}$ mixture was $100 \mathrm{cc}$ so that the total ozone concentration added was $4000 \mu \mathrm{g}$. The exposure time was 40 minutes in according to the half-life (20 minutes) of ozone dissolved in water $(\mathrm{pH} 7)$ at a temperature of $20^{\circ} \mathrm{C}$. No neutralizer of the antibacterial activity of ozonated samples was added. Number of cells per milliliter at the beginning of the test and number of surviving cells after 40 minutes of contact time with ozonated medium were counted.

\section{Results and Discussion}

All cells of the clinical strains of $S$. aureus, $S$. epidermidis, $C$. striatum and, E. faecium suspensions were totally killed. S. agalactiae, E. coli, P. mirabilis, $P$. aeruginosa and all three clinical strains of $K$. pneumoniae were killed slightly less effectively. The detailed results of the test are presented in Table 2.

Bacteria are present in a wide range of environments in which they are exposed to diverse toxic compounds or growth-limiting conditions. These include antibiotics used in the medical environment and agricultural settings. The last few decades have been marked by the constant increase of (multi)drug-resistant clinical isolates to which we have responded by increasing antibiotic dosing. Therefore, antibiotics are present almost everywhere at

Table 1. 13 clinical bacterial strains (6 Gram positive and 7 Gram negative) with different susceptibility to antibiotics and chemotherapeutics, mostly, multiresistant, isolated during routine clinical microbiologic investigations from different specimens (samples of urine, sputum, tracheal aspirates, wound swabs) of hospitalized patients.

\begin{tabular}{lc} 
Clinical bacterial strain & Origin of isolation \\
Gram + & \\
Staphylococcus aureus & Urine \\
Streptococcus epidermidis & Wound swab \\
\hline Streptococcus agalactiae & Wound swab \\
Enterococcus faecium & Urine \\
\hline Enterococcus faecium & Wound swab \\
Corynebacterium striatum & Wound swab \\
\hline Gram - & \\
Escherichia coli & Urine \\
Klebsiella pneumoniae & Urine \\
\hline Klebsiella pneumoniae & Tracheal aspirate \\
Klebsiella pneumoniae & Wound swab \\
\hline Proteus vulgaris & Tracheal aspirate \\
Pseudomonas aeruginosa & Tracheal aspirate \\
\hline Acinetobacter baumannii & Tracheal aspirate \\
\hline
\end{tabular}


Table 2. Antimicrobial activity of ozonated bacterial strain suspensions.

\begin{tabular}{|c|c|c|}
\hline Clinical bacterial strain & Origin of isolation & $\begin{array}{l}\text { Bactericidal } \\
\text { activity (\%) }\end{array}$ \\
\hline \multicolumn{3}{|l|}{ Gram + } \\
\hline Staphylococcus aureus & Urine & $100 \%$ \\
\hline Streptococcus epidermidis & Wound swab & $100 \%$ \\
\hline Streptococcus agalactiae & Wound swab & $94.6 \%$ \\
\hline Enterococcus faecium & Urine & $100 \%$ \\
\hline Enterococcus faecium & Wound swab & $100 \%$ \\
\hline Corynebacterium striatum & Wound swab & $100 \%$ \\
\hline \multicolumn{3}{|c|}{ Mean of bactericidal activity of ozone against Gram positive bacteria: $99.1 \%$} \\
\hline \multicolumn{3}{|c|}{ Gram - } \\
\hline Escherichia coli & Urine & $94.2 \%$ \\
\hline Klebsiella pneumoniae & Urine & $94.4 \%$ \\
\hline Klebsiella pneumoniae & Tracheal aspirate & $98.2 \%$ \\
\hline Klebsiella pneumoniae & Wound swab & $99.6 \%$ \\
\hline Proteus vulgaris & Tracheal aspirate & $95.4 \%$ \\
\hline Pseudomonas aeruginosa & Tracheal aspirate & $96 \%$ \\
\hline Acinetobacter baumannii & Tracheal aspirate & $96 \%$ \\
\hline
\end{tabular}

different concentrations. Although multi-drug resistance still emerges from bacterial exposure to antibiotic concentrations that are higher than the minimal inhibitory concentrations (MIC, defined as the lowest concentration of a drug that inhibits bacterial growth under defined laboratory conditions), the effects of ozone on bacterial physiology and antimicrobial resistance have mostly been disregarded. The results of antimicrobial susceptibility of each clinical strain before (in triplicate) and post-exposure to $\mathrm{O}_{2} \mathrm{O}_{3}$ (in triplicate) are shown in the Supplementary Tables 1-13.

As shown in Supplementary Tables 1-13, our preliminary results demonstrated that the treatment of both Gram positive and Gram negative bacteria with $\mathrm{O}_{2} \mathrm{O}_{3}$ mixture did not generate any antimicrobial resistance. Contrarily, studies in this field have shown that even low antibiotic concentrations affect bacteria at least at four different levels: i) as selectors of resistance (by enriching resistant bacteria within populations and selecting for de novo resistance mutations); ii) as contributors of genetic and fenotypic heterogeneity; iii) as intracellular signals; and iv) as inducers of persistence. A total of 525 AST of which 417 Gramnegative and 108 Gram-positive were produced and compared with the same AST numbers derived from bacteria treated with $\mathrm{O}_{2} \mathrm{O}_{3}$ mixture. The overall category agreement was $100 \%$ for both Gram-positive and Gram-negative bacteria. An interesting agreement in terms of MIC comparison was observed for ceftriaxone, ertapenem, fosfomicin, gentamicin, levofloxacin, piperacillin, piperacillin-tazobactam, ticarcillin-clavulanate, tobramycin, and vancomycin with a lowest MIC in bacteria treated with $\mathrm{O}_{2} \mathrm{O}_{3}$ mixture.

\section{Conclusions}

It is noteworthy that even low antibiotic concentrations affect bacteria to develop antimicrobial resistance. Our preliminary study demonstrated that the treatment of both Gram positive and Gram negative bacteria with $\mathrm{O}_{2} \mathrm{O}_{3}$ mixture can kill bacteria and did not generate any antimicrobial resistance.

\section{References}

1. Horvath M, Bilitzky L, Huttner J. Ozone. New York: Elsevier; 1985. $350 \mathrm{pp}$.

2. Bablon G, Bellamy WD, Bourbigot M-M, et al. Fundamental aspects. In: Langlais G, Reckhow DA, Brink DR, eds. Ozone in water treatment: Application and engineering. Chelsea, Mich., U.S.A.: Lewis Publishers, Inc; 1991. pp 11-132.

3. Katzenelson E, Kletter B, Shuval HF. Inactivation kinetics of viruses and bacteria in water by use of ozone. J Am Water Works Assoc 1974;66:725-9.

4. Kim J-G, Yousef AE, Dave SA. Application of ozone for enhancing the microbiological safety and quality of foods: A review. J Food Prot 1999;62:1071-87.

5. Hoigné J, Bader H. Rate constants of reactions of ozone with organic and inorganic compounds in water. III: Inorganic compounds and radicals. Water Res 1985;19:993.

6. Tomiyasu H, Fukutomi H, Gordon G. Kinetics and mechanism of ozone decomposition in basic aqueous solution. Inorg Chem $1985 ; 24: 2962-6$

7. Wynn CS, Kirk BS, McNabney R. Pilot plant for tertiary treatment of wastewater with ozone. EPA Report R2-73-146, US EPA, Municipal Environ. Cincinnati, Ohio: Water Enineering Research Laboratory; 1973.

8. Wickramanayake GB. Kinetics and mechanism of ozone inactivation of protozoan cysts [PhD dissertation]. Columbus, Ohio: Ohio State University; 1984.

9. Staehelin J, Hoigné J. Decomposition of ozone in water in the presence of organic solutes acting as promoters and inhibitors of radical chain reactions. Environ Sci Technol 1985;19:1206-13.

10. Anbar M, Neta P. A compilation of specific bimolecular rate constants for the reactions of hydrated electrons, hydrogen atoms, and hydroxyl radicals with inorganic and organic compounds in aqueous solutions. Int J Appl Radiat Isotopes 1967;18:493.

11. Perez RR, Nunez SA, Baluja C, Otero ML. Ozonation kinetics of glucosamine and $\mathrm{N}$-acetyl glucosamine in aqueous medium. Ozone Sci Eng 1995;17:463-7.

12. Ishizaki K, Shinriki N, Ikehata A, Ueda T. Degradation of nucleic acids with ozone. I. Degradation of nucleobases, ribonucleosides, and ribonucleoside-5'-monophosphates. Chem Pharm Bull 1981;29:868-72.

13. Kinman RN. Water and wastewater disinfection with ozone: A critical review. Crit Rev Environ Contr 1975;5:141-52.

14. Emerson MA, Sproul OJ, Buck CE. Ozone inactivation of cellassociated viruses. Appl Environ Microbiol 1982;43:603-8.

15. Khadre MA, Yousef AE. Sporicidal action of ozone and hydrogen peroxide, a comparative study. Int J Food Microbiol 2001;71:131-8. 